This document is a manuscript version of the following article:

Title: Bidirectional air turbines for oscillating water column systems: Fast selection applying turbomachinery scaling laws

By: Carolus, Thomas; Moisel, Christoph

Published in: International Journal of Marine Energy

Volume 18, June 2017, Pages 65-77

Publisher: Elsevier | Year: 2017

DOI: 10.1016/j.ijome.2017.03.006

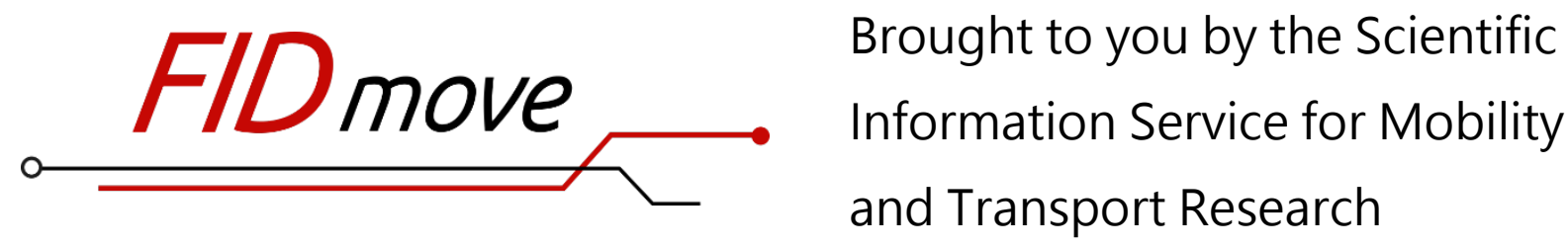

Fachinformationsdienst Mobilitäts- und Verkehrsforschung

Website: www.fid-move.de

Repository: publish.fid-move.de

Contact: publish@fid-move.de

(C) 2017. This manuscript version is made available under the CC-BYNC-ND 4.0 license.

http://creativecommons.org/licenses/by-nc-nd/4.0/ 


\title{
Bidirectional Air Turbines for Oscillating Water Column Systems: Fast Selection Applying Turbomachinery Scaling Laws
}

\author{
Thomas H. Carolus \\ Institut für Fluid und Thermodynamik \\ University of Siegen \\ 57068 Siegen, Germany \\ Email: thomas.carolus@uni-siegen.de
}

\author{
Christoph Moisel \\ Institut für Fluid und Thermodynamik \\ University of Siegen \\ 57068 Siegen, Germany \\ Email: christoph.moisel@uni-siegen.de
}

\begin{abstract}
The collector of an oscillating water column system (OWC) for wave energy utilization requires a bidirectional turbine that copes with pneumatic power while providing specified impedance or, in terms of an OWC designer, "damping". Damping is realized by keeping to a specific flow rate through the turbine at a given pressure head due to the individual performance characteristic of the turbine. With the number of turbine designs increasing designers of OWC systems are facing more options to select and dimension a bidirectional turbine. Energy yield, size and hence cost of the turbine and electric generator, operational behaviour, envisaged control strategy and noise emitted by the turbine are possible criteria for selection.

The primary objective of this paper is to describe a simple procedure for making a first choice of a turbine for a particular OWC application. Here we confine ourselves to a family of reaction type of turbines (axial-flow Wells and mixed-flow turbines by Moisel) with their approximately linear pressure head/volume flow rate characteristics. Starting point is the set of non-dimensional steady-state characteristics of each turbine in the family. Utilizing standard scaling laws and a very simple time domain model for the cyclic turbine operation (i.e. based one single sea state and turbine operation assumed to be fixed rotational speed), first estimates of turbine size and rotor speed, number for stages or flows, and performance curves can be determined. The resulting turbine may also serve as a starting configuration for a refined analysis, e.g. the optimization of the turbine and the complete OWC system, utilizing more complex stochastic models. Three case studies illustrate the application of the method: selection and scaling of turbines, effect of collector parameters, turbines in series and parallel.
\end{abstract}

\section{Keywords - Bidirectional Air Turbine, Oscillating Water Column, Wave Energy}

\author{
Nomenclature \\ $c_{0} \quad$ speed of sound \\ $d \quad$ diameter of turbine rotor $[\mathrm{m}]$ \\ $D_{t s} \quad$ reciprocal slope of $I^{\&}=f\left(\Delta p_{t s}\right)$ characteristic $\left[\left(\mathrm{m}^{3} / \mathrm{s}\right) / \mathrm{Pa}\right]$ \\ Ma Mach number [-] \\ $p \quad$ collector gauge pressure $[\mathrm{Pa}]$ \\ $P \quad$ power [W] \\ Re Reynolds number [-] \\ $n \quad$ rotational speed, i.e. number of rotor revolutions per unit time [rps, rpm] \\ \& $\quad$ volume flow rate $\left[\mathrm{m}^{3} / \mathrm{s}\right]$
}




$\begin{array}{ll}t & \text { time }[\mathrm{s}] \\ T_{m} & \text { period of pressure oscillation }[\mathrm{s}] \\ z_{\text {stage }} & \text { number of turbine stages }[-] \\ z_{\text {flow }} & \text { number of turbine flows [-] } \\ Z & \text { impedance }\left[\mathrm{Pa} /\left(\mathrm{m}^{3} / \mathrm{s}\right)\right] \\ \Delta p & \text { pressure head }[\mathrm{Pa}] \\ \eta & \text { efficiency }[-] \\ \lambda & \text { power coefficient }[-] \\ v & \text { kinematic viscosity of air }\left[\mathrm{m}^{2} / \mathrm{s}\right] \\ \rho & \text { density of air }\left[\mathrm{kg} / \mathrm{m}^{3}\right] \\ \phi & \text { flow rate coefficient }[-] \\ \psi & \text { pressure coefficient }[-]\end{array}$

\section{Subscripts}

$\begin{array}{ll}\text { coll } & \text { collector } \\ \text { crit } & \text { critical } \\ \text { DP } & \text { design point } \\ \text { max } & \text { maximal } \\ m p & \text { maximal power (= limit of stall free operation) } \\ \text { opt } & \text { optimal } \\ \text { OP } & \text { nominal turbine operating point } \\ p & \text { pneumatic } \\ r m s & \text { root mean square } \\ \text { shaft } & \text { at shaft } \\ t s & \text { total-to-static }\end{array}$

Superscripts

$\wedge \quad$ amplitude, peak

- $\quad$ time average

Abbreviations

OWC Oscillating Water Column 


\section{Introduction}

The principle of an oscillating water column (OWC) is used in power plants which extract the energy of ocean waves and convert it into shaft power of a bidirectional air turbine, Fig. 1. $p$ is the static gauge pressure inside the air chamber of the collector (with reference to the constant barometric pressure $p_{b}$ outside in the free atmosphere). It oscillates with time due to the water surface wave motion and causes a volume flow rate $\mathbb{\&}_{\text {through an }}$ upper opening. Typically the designer of an OWC specifies an impedance or so-called "damping" (i.e. the ratio of pressure and volume flow rate) at this opening that is required for maximizing the pneumatic power, eventually seen by a turbine.

If the air chamber is large as compared to the size of the turbine (which is in general the case), the air kinetic energy in the chamber not close to the turbine is very small and can be neglected. Hence, $p$ is equivalent to the total-to-static pressure head $\Delta p_{t s}$ driving the turbine. In the jargon of a turbine developer total-to-static indicates that the head is the difference of total pressure at the turbine inlet and the static pressure at the outlet - the dynamic pressure at the turbine outlet is fully dissipated and called the "exit loss". \& is the volume flow rate the turbine must take, i.e. its "swallowing capacity".

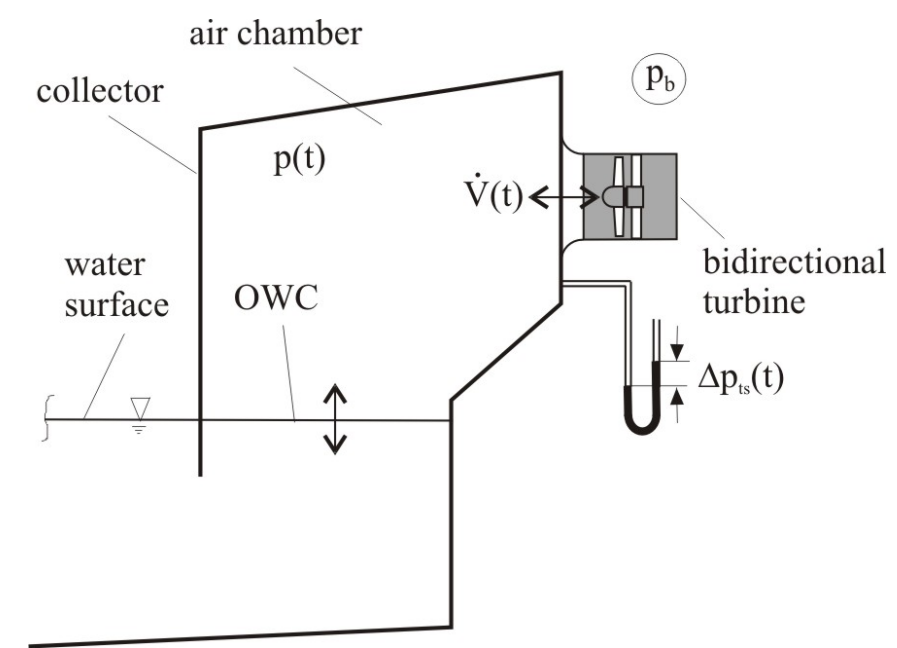

Figure 1. Oscillating water column system (schematically).

Only a few types of bidirectional air turbines were available to early designers of OWC systems. In some cases this led to out-of-tune OWC-systems, because the turbine was "over-" or "under-damping" the collector. The situation has changed over the past years. Designers of modern OWC systems have many more choices of bidirectional turbine types than in the past. The classical axial Wells turbine [1], i.e. a reaction turbine requiring airfoil-type blades with their lift being a key parameter, or in other words a "lift-based"' turbine, have experienced the most research and development efforts during the past 40 years, see e.g. Raghunathan [2] and a couple of more recent contributions by Starzmann and the authors of the present paper, refs [3] - [7]. The reaction working principle has also been applied to radial and very recently to mixed-flow (i.e. diagonal) turbine rotors, refs [8] - [10]. As an alternative a zero-reaction, so-called 'impulse type' turbine for bidirectional flow, originally invented by Babintsev [11], is known. Recent overviews on bidirectional air turbines for use in OWCs have been published by Setoguchi and Takao [12], Falcão and Gato [13] and Curran and Folley [14]. 
The objective of our work is a simple procedure for a first dimensioning of a turbine - here exclusively reaction turbines with their approximately linear pressure head/volume flow rate characteristics - for an envisaged OWC system. Our procedure is based on the application of standard turbomachinery scaling laws and an estimate of the maximum energy yield from an OWC system under simplifying assumption. We start with given sets of measured performance characteristics and aim at maximum energy yield for one single specific sea state. The turbine operation is assumed to be fixed rotational speed. The latter two simplifying assumptions do not reflect fully the complexity of a real wave climate and state-of-the art turbine speed control strategies but are an easy to understand access for a first and preliminary selection of an OWC turbine. We refer to e.g. Falcão [15] and Falcão et al. [16] for a more complex stochastic model of the energy conversion process from wave to air turbine and further optimization of the complete OWC system including the consideration of impulse turbines. The acoustic performance is not considered, for that we refer to Starzmann [5].

\section{System analysis}

By contrast to e.g. a hydropower installation where the head of the turbine is kept constant or nearly constant, the turbine in an OWC system experiences an extremely unsteady head. Hence, a careful distinction between instantaneous, peak and time averaged quantities has to be made. In addition, the unsteady operation implies that the overall energy yield of the turbine is determined by its complete performance characteristic, not only by one operating point. For the sake of clarity the collector and the turbine are analyzed separately in the subsequent sections of this paper. This not only helps to understand the fundamental physics but also elucidates the individual responsibilities of the OWC and the turbine designer.

\subsection{Collector}

At a given sea state the static pressure in the collector varies cyclically with time - in an idealization - sinusoidally as

$$
p(t)=\hat{p} \sin \frac{2 \pi}{T_{m}} t
$$

$\hat{p}$ is the amplitude, $T_{m}$ the period of the collector pressure oscillation. Frequently, the collector designer specifies the peak pressure (or pressure amplitude) $\hat{p}$, or alternatively the root-mean-square pressure

$$
p_{r m s} \equiv \sqrt{\frac{1}{t^{*}} \int_{t_{0}}^{t_{0}+t^{*}} p^{2}(t) d t}=\frac{1}{\sqrt{2}} \hat{p}
$$

where $t^{*}$ is a multiple of a half wave period or much larger than a wave period. $p(t)$ acts as driving pressure for a time depending volume flow rate of air through the opening of the collector $\&(t)$. The associated instantaneous pneumatic power available at the opening is

$$
P_{p, \text { coll }}(t)=\&(t) \cdot p(t)
$$

the peak pneumatic power

$$
\hat{P}_{p, \text { coll }}=\hat{p}^{\hat{\&}}
$$

and the time average pneumatic power

$$
\bar{P}_{p, \text { coll }} \equiv \frac{1}{t^{*}} \int_{t_{0}}^{t_{0}+t^{*}} p(t) \cdot I \&(t) d t .
$$


The collector requires a specified impedance at its opening in Fig. 1

$$
Z \equiv \frac{\hat{p}}{\hat{\&}} .
$$

If the impedance is not a function of $p$ and hence of time $t$, then the volume flow rate through the opening simply becomes

$$
\&(t)=\hat{\&} \sin \omega t=\frac{\hat{p}}{Z} \sin \frac{2 \pi}{T_{m}} t
$$

and the time average pneumatic power

$$
\bar{P}_{p, \text { coll }}=\frac{p_{r m s}^{2}}{Z}=\frac{1}{2} \frac{\hat{p}^{2}}{Z}=\frac{1}{2} \hat{p} \hat{\&}=\frac{1}{2} \hat{P}_{p, \text { coll }} .
$$

\subsection{Turbine}

Frequently turbine developers present their experimentally determined turbine performance characteristics in terms of non-dimensional performance coefficients. We prefer the widely used flow rate, pressure head and shaft power coefficient

$$
\phi \equiv \frac{L^{\&}}{\frac{\pi^{2}}{4} d^{3} n}, \psi_{t s} \equiv \frac{\Delta p_{t s}}{\frac{\pi^{2}}{2} d^{2} n^{2} \rho}, \lambda \equiv \frac{P_{\text {shaft }}}{\frac{\pi^{4}}{8} d^{5} n^{3} \rho} .
$$

$d$ is a measure of the geometrical size of the turbine (usually the outer rotor diameter), $n$ the rotational speed or number of revolutions per unit time of the rotor, $\rho$ the mean density of the air through the turbine. Fig. 2 shows a set of idealized non-dimensional characteristics which are typical for all bidirectional reaction type air turbines (as is the case for the axial-flow Wells or mixed-flow turbine by Moisel). Coming from zero pressure head the onset of the desired shaft power is at $\psi_{t s, 0}$ - not at $\psi_{t s}=0$ because of internal losses. The shaft power increases with pressure head up to the stall point. There the shaft power is maximal. Beyond stall (i.e. $\psi_{t s, m p}$ ), in general an abrupt and substantial decrease of shaft power is observed. Details of the stalled operational regime are not shown in Fig. 2.

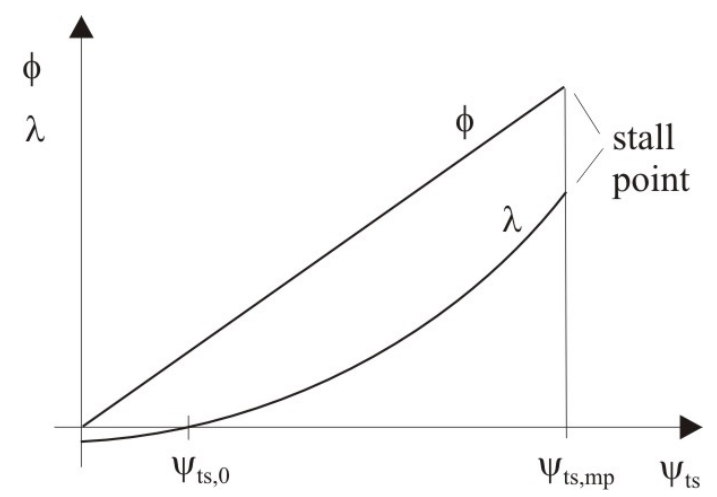

Figure 2. Idealized aerodynamic non-dimensional steady-state characteristics of a bidirectional reaction turbine

Non-dimensional performance curves are extremely useful because they represent the performance of a turbine type independently of its absolute dimension, speed and fluid density. For any values of $d, n$ and $\rho$ the dimensional performance curves can be derived easily as long as the turbine is scaled up or down, keeping its geometry fully similar. Beside geometrical similarity equal Reynolds- and Mach number 


$$
\operatorname{Re}=\frac{\pi d^{2} n}{v}, \mathrm{Ma} \equiv \frac{\pi d n}{c_{0}}
$$

of the original and the scaled up or down turbine are required, which, unfortunately, can not always be achieved. This has been addressed in some detail in Falcão and Henriques [17]. It is, however, often sufficient to ensure values of Reynolds number above and Mach number below a critical value.

Transient flow phenomena in the turbine are negligible for typical frequencies involved in OWC-systems - a quantitative justification for that is given by Moisel and Carolus in [18]. Hence, precisely measured steady-state characteristics are sufficient in most cases, although standards for bidirectional turbine test rigs and measurement procedures do not exist at present. This has also been addressed in [18].

\subsection{Synthesis of collector and turbine}

The key assumption in this paper is that the turbine design point $\left(\Delta p_{t s, D P}, I_{D P}^{\&}\right)$ equals the collector peak pressure and peak flow rate at the sea state considered. For some collectors a multi-stage turbine or multi-flow assembly may be suitable. Hence, given the number of stages $z_{\text {stage }}$ and flows $z_{\text {flow }}$, the turbine stage design point becomes

$$
\begin{aligned}
& \Delta p_{t s, D P}=\frac{\hat{p}}{z_{\text {stage }}}, z_{\text {stage }}=1,2, \ldots \\
& \&_{D P}=\frac{\hat{\&}}{z_{\text {flow }}}, z_{\text {flow }}=1,2, \ldots .
\end{aligned}
$$

This implies that the reciprocal slope $D_{t s, D P}$ of the $\mathbb{L}^{\&}=f\left(\Delta p_{t s}\right)$ characteristic at the design point is related to the collector impedance as

$$
D_{t s, D P} \equiv \frac{\Delta p_{t s, D P}}{L_{D P}^{\&}}=Z \frac{z_{\text {flow }}}{z_{\text {stage }}} .
$$

In principle, any pair of $\left(\psi_{t s}, \phi\right)$-values of the non-dimensional characteristics of a given turbine type can be chosen as nominal turbine operating point $\left(\psi_{t s, O P}, \phi_{O P}\right)$. One can, however, imagine various objectives for selecting $\left(\psi_{t s, O P}, \phi_{O P}\right)$, e.g.:

- $\quad$ Maximizing the average efficiency $\bar{\eta}$ and hence the energy yield

- Maximizing the distance of the design point to the maximum power operating point, i.e. to stall

- $\quad$ Aiming at a certain turbine size $d$ or turbine speed $n$

- Aiming at a low noise operation.

(In the case studies reported in the third section of this paper we will aim at maximum average efficiency $\bar{\eta}$ only.) Solving eqs. (9) and (10) for given values of the flow rate and pressure head coefficients, $\phi_{\mathrm{OP}}$ and $\psi_{t s, O P}$, yields the rotor diameter

$$
d=\sqrt[4]{\frac{8 \rho}{\pi^{2}} \frac{\psi_{t s, O P}}{\phi_{O P}{ }^{2}} \frac{{l_{D P}{ }^{2}}_{\Delta p_{t s, D P}}}{\Delta p^{2}}}
$$

and the rotational speed

$$
n=\frac{4}{\pi^{2}} \frac{\nu_{D P}^{\&}}{\phi_{O P} d^{3}}
$$


of the turbine type the $\left(\psi_{t s}, \phi\right)$-characteristic belongs to. These are the two key equations for the case studies in the third section of this paper.

Eventually, with this diameter and speed known, the dimensional characteristics $\&=f\left(\Delta p_{t s}\right)$ and $P_{\text {shaft }}=f\left(\Delta p_{t s}\right)$ are obtained. Fig. 3 illustrates schematically the interplay of collector and turbine: the cyclically varying pressure in the collector $p(t)$ equals the argument $\Delta p_{t s}$ in the steady-state turbine performance curves.

Finally, with the $\&=f\left(\Delta p_{t s}\right)$ and $P_{\text {shaft }}=f\left(\Delta p_{t s}\right)$ characteristics known, the turbine's total-static-efficiency characteristic

$$
\eta_{t s}\left(\Delta p_{t s}\right) \equiv \frac{P_{\text {shaft }}}{\& \Delta p_{t s}}
$$

can be determined. Moreover, the instantaneous shaft power $P_{\text {shaft }}(t)$ can be computed from the $P_{\text {shaft }}=f\left(\Delta p_{t s}\right)$ characteristic. This allows determining the time average shaft power

$$
\bar{P}_{\text {shaft }} \equiv \frac{1}{t^{*}} \int_{t_{0}}^{t_{0}+t^{*}} P_{\text {shaft }}(t) d t
$$

where $t^{*}$ is a multiple of a half wave period or much larger than a wave period, and eventually the average efficiency of the energy transformation from the collector to the turbine shaft

$$
\bar{\eta} \equiv \frac{\bar{P}_{\text {shaft }}}{\bar{P}_{p, \text { coll }}} .
$$

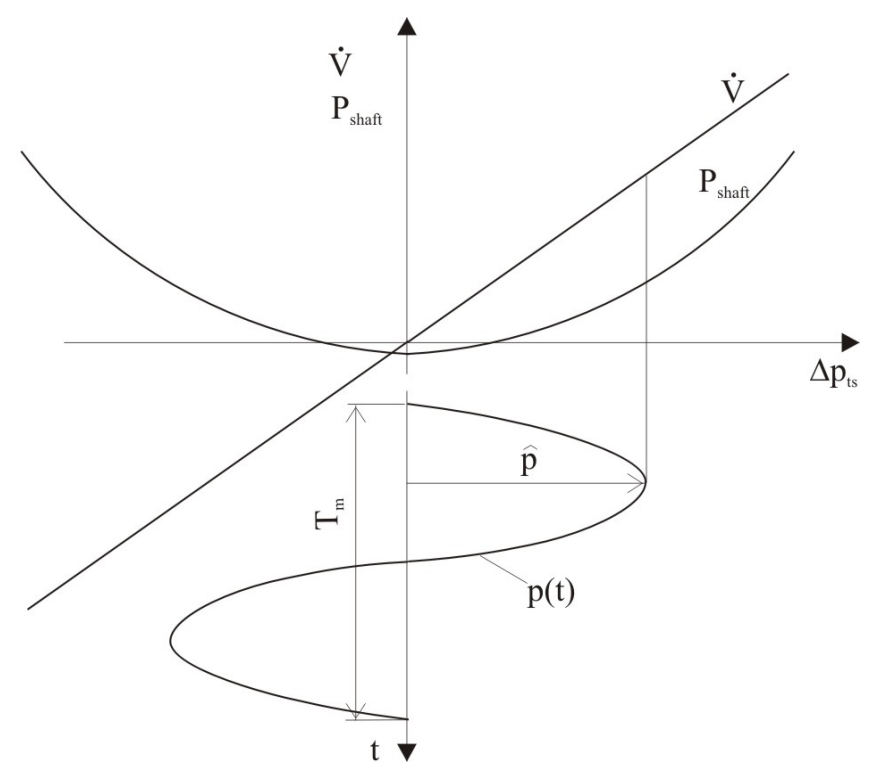

Figure 3. Sinusoidally varying collector pressure acting on a turbine with its state performance curves for $d$ and $n=$ const. (schematically).

$\eta_{t s}$ and $\bar{\eta}$ must not be confused. $\eta_{t s}$ assesses how well the turbine converts pneumatic into shaft power at a specific steady-state point of operation, i.e. it is a measure of the turbine's aerodynamic losses - to be addressed by the turbine designer. By contrast $\bar{\eta}$ describes the effectiveness of the pneumatic energy transformation from the collector to the turbine shaft. It is an integral quantity which includes turbine losses along the complete characteristic from 0 to design pressure head. It also depends on the choice of the nominal turbine operating point 
$\left(\psi_{t s, O P}, \phi_{O P}\right)$ which is in the responsibility of the collector or OWC-system designer. In this paper we exclusively deal with $\bar{\eta}$.

\section{Case studies}

In the subsequent case studies we demonstrate the selection and parameterization of turbines from a family of turbine types. We restrict the family to four turbine types compiled in Tab. 1, arbitrarily chosen from a more comprehensive data base of turbines developed and model-tested at the University of Siegen [19]. The rotor diameter of these model-scale axial-flow rotors was $400 \mathrm{~mm}$, of the mixed-flow rotor $350 \mathrm{~mm}$; more details of all geometrical parameters are documented in refs [5] and [10].

Table 1. Family of bidirectional turbines considered in the case studies (developed and performance tested at the University of Siegen [19])

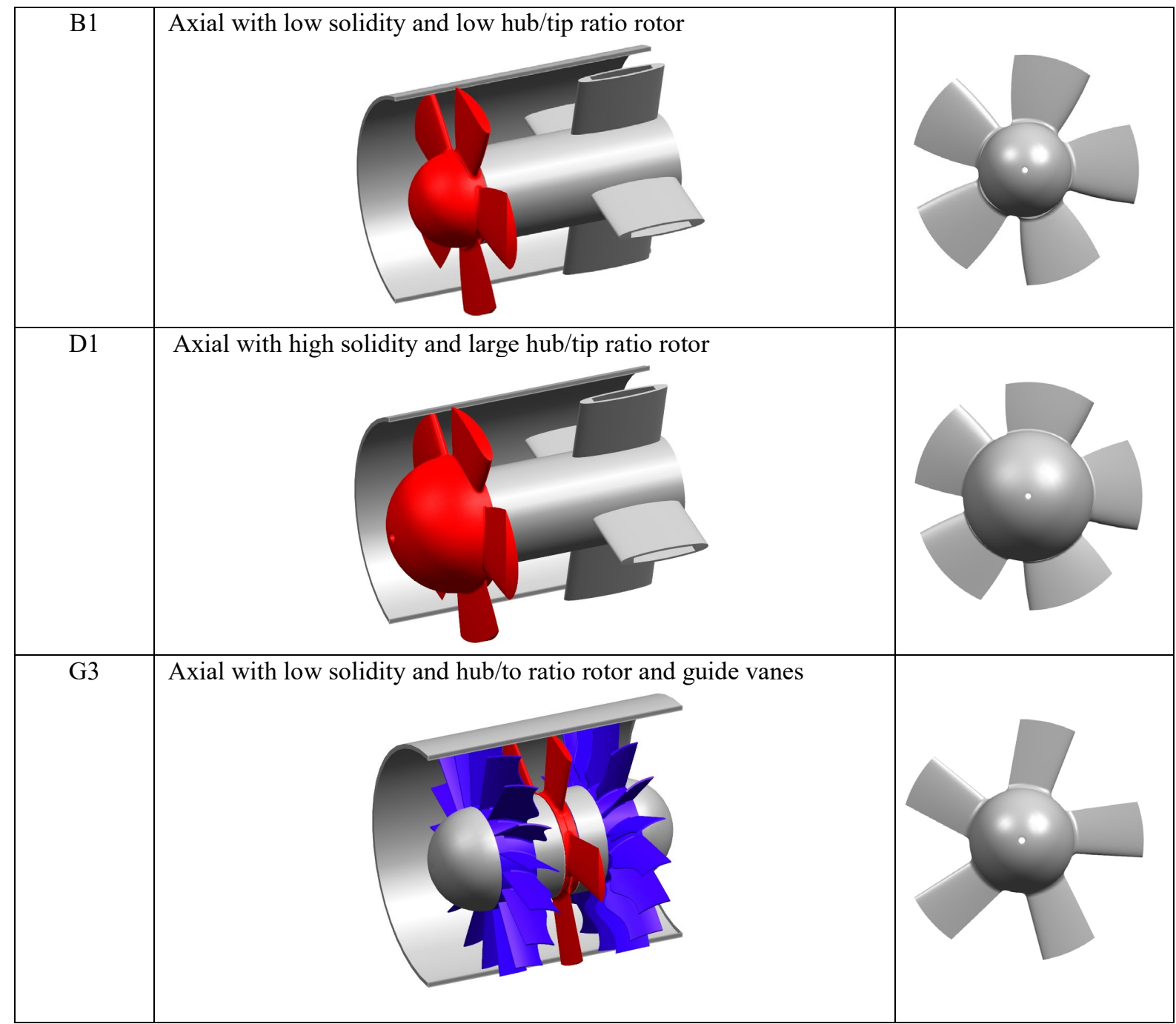




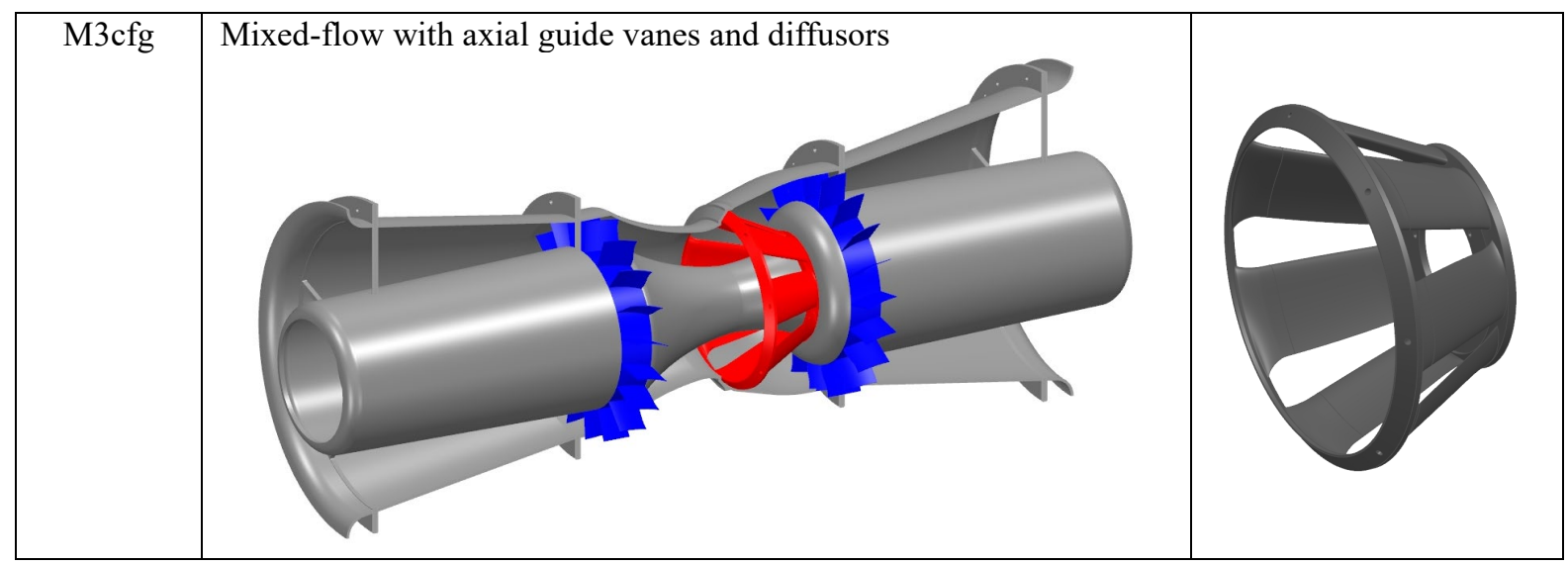

Fig. 4 presents their non-dimensional performance curves, measured for values of Mach and Reynolds numbers generally accepted to be beyond and below critical, respectively. In contrast to Fig. 2, where the idealized $\phi=f\left(\psi_{t s}\right)$ characteristic is a straight line through the origin of the coordinate system, real $\phi=f\left(\psi_{t s}\right)$ characteristics are slightly non-linear, i.e. their slope varies with $\psi_{t s}$.
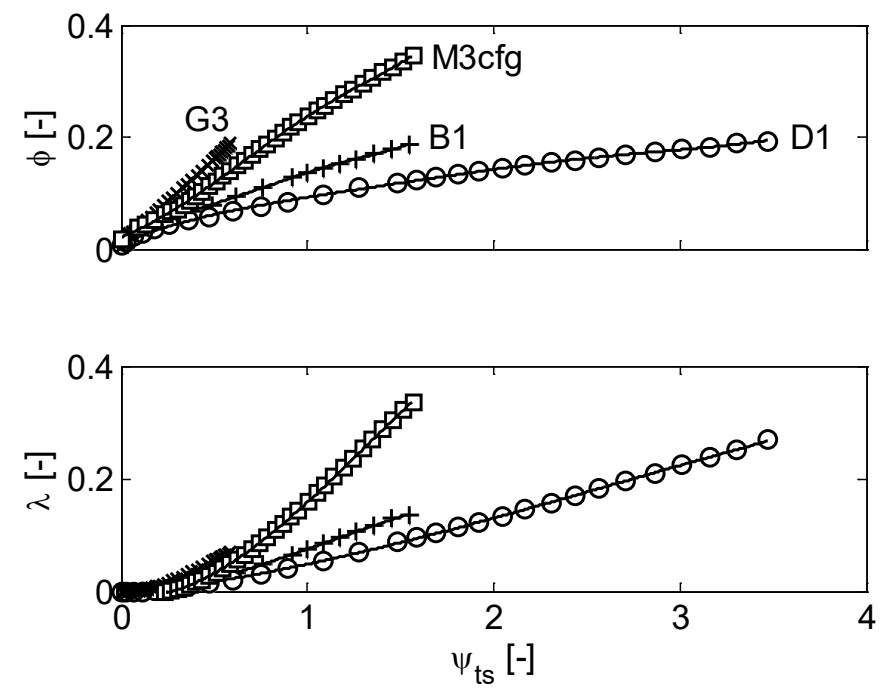

Figure 4. Experimentally determined non-dimensional performance curves of the family of turbines from Tab. 1

\subsection{Selection and scaling of turbines}

With this case study we demonstrate the procedure of turbine selection from a family of turbines. As an example we assume a specification of the OWC-collector in terms of the quantities at its opening:

- $\quad$ peak pneumatic power $\hat{P}_{p, \text { coll }}=100 \mathrm{~kW}$

- impedance $Z=250 \mathrm{~Pa} /\left(\mathrm{m}^{3} / \mathrm{s}\right)$

For the turbine we assume:

- $\mathrm{Ma}_{\text {crit }}=0.5$

- $\rho=1,2 \mathrm{~kg} / \mathrm{m}^{3}$

The lower diagram in Fig. 5 represents the graphs of resulting $(d, n)$ combinations for the four turbine types, scaled to meet the collector specification. Depending on the turbine type they differ considerably. For instance, 
the mixed flow turbine M3cfg requires the smallest rotor sizes, the axial D1 with high solidity and large hub/tip ratio rotor the largest, whereas the opposite is true for the rotational speed. The solid lines indicate $(d, n)$ pairs for which the Mach number is below the permissible value Ma $\mathrm{Mrit}_{\text {, }}$, whereas the dotted lines indicate supercritical Mach numbers that should be avoided. All results are assumed to be independent of Reynolds number, which is assumed to be well above the critical value. The upper diagram shows the resulting average efficiency for each combination. Clearly, there is a maximum for each turbine type resulting in an optimal pair $\left(d_{\text {opt }}, n_{\text {opt }}\right)$ as summarized in Tab. 2. The axial-flow turbine with guide vanes G3 requires the largest rotational speed but offers the highest maximum average efficiency of all turbines. The Mach number, however, is with 0.45 already close to being critical.Fig. 6 indicates the nominal turbine operating point $\left(\psi_{t s, O P}, \phi_{O P}\right)$ associated with $\left(d_{o p t}, n_{o p t}\right)$. Now the distance of the operating point to the turbines' maximum power point becomes evident. If one aimed at a large stall free overload capacity, clearly turbine type D1 is a favourable design, since $\psi_{t s, m p} / \psi_{t s, D P}=4.4$; that means this turbine can cope with 4.4 times the nominal design pressure head before stalling without the need to increase its rotational speed. On the other hand this turbine provides the lowest maximum average efficiency (upper diagram in Fig. 5).
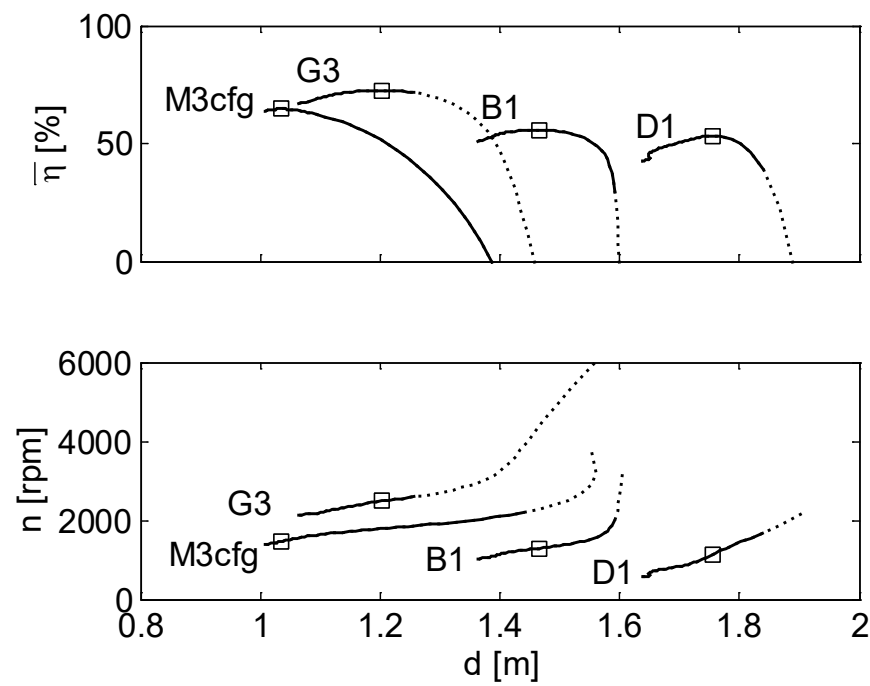

Figure 5. The family of turbines from Tab. 1, scaled for a collector with $\hat{P}_{p, \text { coll }}=100 \mathrm{~kW}$ and $Z=250$ $\mathrm{Pa} /\left(\mathrm{m}^{3} / \mathrm{s}\right)$; upper diagram: Average efficiency as a function of turbine diameter, $\sim$ maximum average efficiency; lower diagram: Possible pairs of $d$ and $n, \sim\left(d_{\text {opt }}, n_{\text {opt }}\right) ; \cdots \cdot . \cdot \mathrm{Ma}>\mathrm{Ma}_{\text {crit }}$

Table 2. Optimal size and rotational speed of the family of turbines scaled for a collector with $\hat{P}_{p, \text { coll }}=100 \mathrm{~kW}$ and $Z=250 \mathrm{~Pa} /\left(\mathrm{m}^{3} / \mathrm{s}\right)$

\begin{tabular}{|c|c|c|c|c|c|}
\hline $\begin{array}{c}\text { turbine } \\
\text { type }\end{array}$ & $\begin{array}{c}d_{\text {opt }} \\
{[\mathrm{m}]}\end{array}$ & $\begin{array}{c}n_{\text {opt }} \\
{[\mathrm{rpm}]}\end{array}$ & $\begin{array}{c}\bar{\eta}_{\max } \\
{[\%]}\end{array}$ & $\begin{array}{c}\mathrm{Ma} \\
{[-]}\end{array}$ & $\begin{array}{c}\psi_{t s, m p} / \psi_{t s, D P} \\
{[-]}\end{array}$ \\
\hline B1 & 1.47 & 1239 & 55.7 & 0.29 & 1.8 \\
\hline D1 & 1.76 & 1121 & 53.4 & 0.30 & 4.4 \\
\hline G3 & 1.20 & 2486 & 72.7 & 0.45 & 1.7 \\
\hline M3cfg & 1.03 & 1463 & 64.7 & 0.23 & 1.2 \\
\hline
\end{tabular}



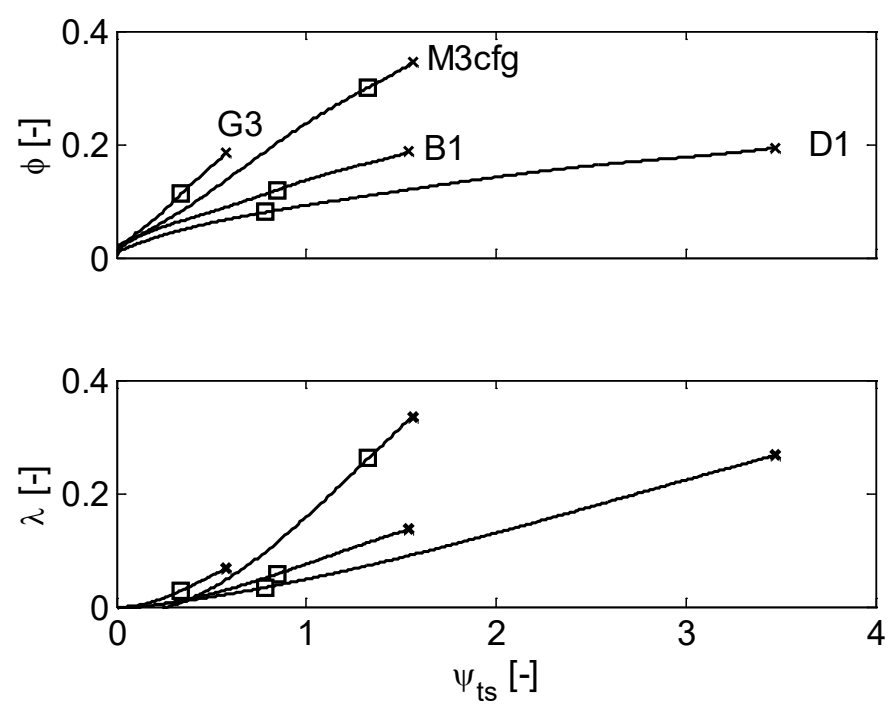

Figure 6. Non-dimensional characteristics and $\sim$ nominal operating points of the family of turbines scaled with $\left(d_{\text {opt }}, n_{\text {opt }}\right)$ for a collector with $\hat{P}_{p, \text { coll }}=100 \mathrm{~kW}$ and $Z=250 \mathrm{~Pa} /\left(\mathrm{m}^{3} / \mathrm{s}\right) ; \mathbf{x}$ maximum power points

Finally, Fig. 7 shows the dimensional characteristics of the family of turbines scaled to $D_{o p t}$ and operated with $n_{\text {opt }}$. As intended each $L^{\&}=f\left(\Delta p_{t s}\right)$ characteristic is running through the design point $\left(5000 \mathrm{~Pa} / 20 \mathrm{~m}^{3} / \mathrm{s}\right)$ which corresponds to the input data $\hat{P}_{p, \text { coll }}=100 \mathrm{~kW}$ and $Z=250 \mathrm{~Pa} /\left(\mathrm{m}^{3} / \mathrm{s}\right)$ according to eqs. (4) and (6).

It is worthwile comparing the power figures in this case study: We started with a pneumatic peak power $\hat{P}_{p, \text { coll }}=$ $100 \mathrm{~kW}$ available from the collector. The turbine type D1, for instance, causes an average pneumatic power $\bar{P}_{p, c o l l}=54.5 \mathrm{~kW}$. This is slightly higher than expected from eq. (8) $(50 \mathrm{~kW})$ due to the non-linearity of the real $\phi=f\left(\psi_{t s}\right)$ characteristic of turbine D1. The turbine D1 develops a peak shaft power $\hat{P}_{\text {shaft }}=54.0 \mathrm{~kW}$ as can easily be derived from its $\lambda=f\left(\psi_{t s}\right)$ characteristic. With the average efficiency of the complete energy transformation as defined by eq. (21) of $53.4 \%$ we end up with an average shaft power of the turbine $\bar{P}_{\text {shaft }}=29.1$ $\mathrm{kW}$. Occasionally the different power quantities are confused, but these figures illustrate impressively that one has to distinguish these quantities carefully in order to estimate the energy yield of an OWC accurately. 

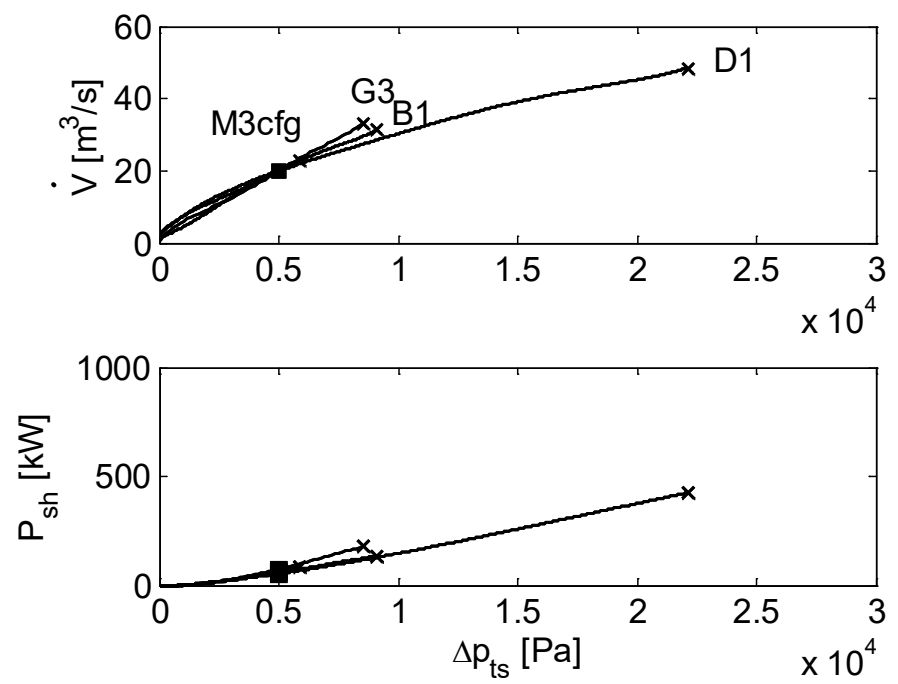

Figure 7. Dimensional characteristics and $\sim$ design points of the family of turbines scaled with $\left(d_{\text {opt }}, n_{\text {opt }}\right)$ for a collector with $\hat{P}_{p, \text { coll }}=100 \mathrm{~kW}$ and $Z=250 \mathrm{~Pa} /\left(\mathrm{m}^{3} / \mathrm{s}\right) ;$ x maximum power points

\subsection{Effect of collector parameters}

In this case study we study the effect of two different OWC-collector scenarios: The design pneumatic power, available from either collector, shall be equal and is quantified in terms of peak power. Each collector, however, requires a different value of impedance. The input data are compiled in Tab. 3. They yield the design points for a single stage, single flow turbine as in the two right columns of Tab. 3 . The mean air density is $\rho=1.2 \mathrm{~kg} / \mathrm{m}^{3}$ for both scenarios. The turbine type chosen is the axial with high solidity and large hub/tip ratio rotor D1 in Tab. 1 with its dimensionless performance curves as in Fig. 4.

All combinations of $d$ and $n$ that meet the design target are depicted in the lower graph of Fig. 8. In this case study we again seek optimal values $\left(d_{o p t}, n_{o p t}\right)$, i.e. those that provide the maximal average efficiency $\bar{\eta}_{\max }$. The results are summarized in Tab. 4. Cleary the parameters of the collector severely affect size, rotational speed and Mach number of the turbine.

Table 3. Given collector scenarios

\begin{tabular}{|c|ccc|cc|}
\hline Scenario & \multicolumn{3}{|c|}{ Collector } & \multicolumn{2}{c|}{ Turbine design point } \\
\hline & $\hat{P}_{p, \text { coll }}$ & $Z$ & $\hat{p}$ & $\Delta p_{t s, D P}$ & $\mathcal{I}_{D P}$ \\
& {$[\mathrm{~kW}]$} & {$\left[\mathrm{Pa} /\left(\mathrm{m}^{3} / \mathrm{s}\right)\right]$} & {$[\mathrm{Pa}]$} & {$\left[\mathrm{m}^{3} / \mathrm{s}\right]$} \\
\hline (a) & 100 & 250 & 5,000 & 5,000 & 20 \\
\hline (b) & 100 & 1,000 & 10,000 & 10,000 & 10 \\
\hline
\end{tabular}



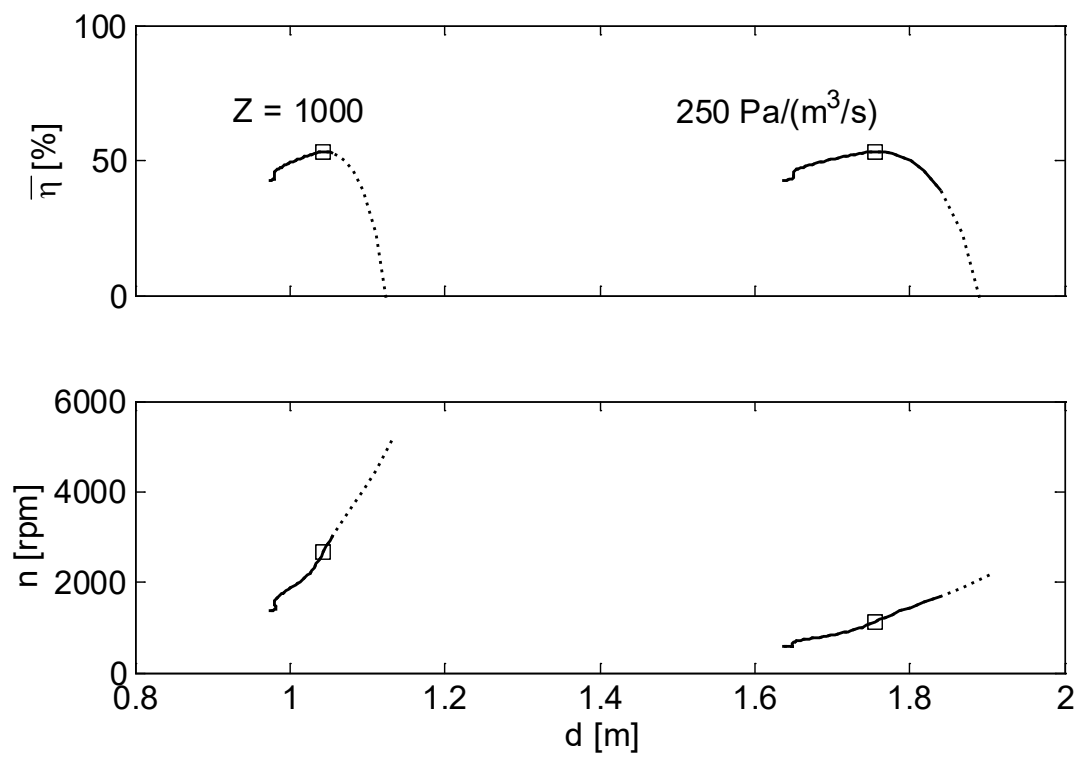

Figure 8. Upper: Average efficiency as a function of turbine diameter, $\sim$ maximum average efficiency ; lower: Possible pairs of $d$ and $n$ for the two scenarios with different collector impedance, $\sim\left(d_{o p t}, n_{\text {opt }}\right) ; \cdots \cdots . . \mathrm{Ma}>$ $\mathrm{Ma}_{\text {crit }}$,

Table 4. Optimal size and rotational speed of turbine type D1 designed for scenarios (a) and (b)

\begin{tabular}{|c|c|c|c|c|c|c|}
\hline Scenario & $\begin{array}{c}Z \\
{\left[\mathrm{~Pa} /\left(\mathrm{m}^{3} / \mathrm{s}\right)\right]}\end{array}$ & $\begin{array}{c}d_{\text {opt }} \\
{[\mathrm{m}]}\end{array}$ & $\begin{array}{c}n_{\text {opt }} \\
{[\mathrm{rpm}]}\end{array}$ & $\begin{array}{c}\bar{\eta}_{\text {max }} \\
{[\%]}\end{array}$ & $\begin{array}{c}\text { Ma } \\
{[-]}\end{array}$ & $\begin{array}{c}\psi_{t s, m p} / \psi_{t s, D P} \\
{[-]}\end{array}$ \\
\hline (a) & 250 & 1.76 & 1121 & 53.4 & 0.30 & 4.4 \\
\hline (b) & 1,000 & 1.04 & 2667 & 53.4 & 0.42 & 4.4 \\
\hline
\end{tabular}

\subsection{Turbines in series and parallel}

In this case study a dual-stage and a two-flow turbine assembly are compared to the benchmark configuration "single-flow, single-stage". In general a multi-flow installation is easy to realize since one has to attach just a number of turbines to the collector, Fig. 9. A multi-stage version of most bidirectional turbine types requires modification of the turbine design. For instance an axial-flow turbine without guide vanes for rectification of the outlet flow would cause an inlet flow to the second stage with swirl and hence degrade its performance. From our family of turbines type G3 is the most suitable for a dual-stage assembly, since it features already guide vanes, lower sketch in Fig. 9. In this study we assume that all non-dimensional performance curves of each stage remain the same as in the single-stage version. 

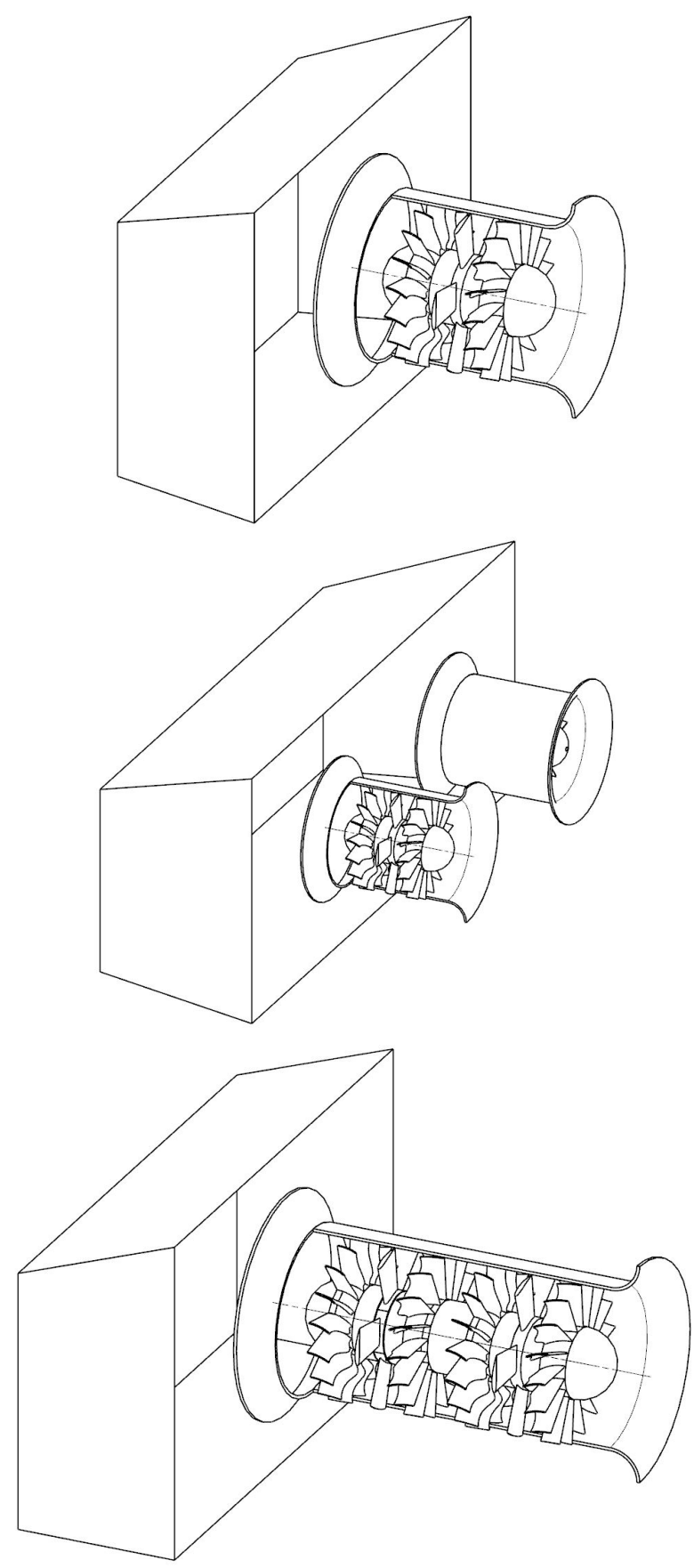

Figure 9. Variation of the number of turbine flows and stages; upper: single-flow, single-stage; middle: twoflow, single-stage; lower: single-flow, dual-stage (schematically).

Tab. 5 summarizes resulting figures. As compared to the benchmark the dual-flow leads to much smaller turbines which are to be operated with higher rotational speed. The Mach number remains the same. In contrast, the dual-stage configuration requires comparably large rotor diameters but the turbine runs at drastically decreased rotational speed. If there is a need to decrease the Mach number, the dual stage configuration is to be preferred.

Table 5. Comparison of optimal size and rotational speed of dual-flow and dual-stage turbine type G3; $\hat{P}_{p, c o l l}=$ $100 \mathrm{~kW}, Z=250 \mathrm{~Pa} /\left(\mathrm{m}^{3} / \mathrm{s}\right)$ 


\begin{tabular}{|c|c|c|c|c|}
\hline$z$ flow & $z_{\text {stage }}$ & $\begin{array}{c}d_{\text {opt }} \\
{[\mathrm{m}]}\end{array}$ & $\begin{array}{c}n_{\text {opt }} \\
{[\mathrm{rpm}]}\end{array}$ & $\begin{array}{c}\text { Ma } \\
{[-]}\end{array}$ \\
\hline 1 & 1 & 1.20 & 2486 & 0.45 \\
\hline 2 & 1 & 0.85 & 3515 & 0.45 \\
\hline 1 & 2 & 1.43 & 1478 & 0.32 \\
\hline
\end{tabular}

\section{Summary and conclusions}

The aerodynamic design of a new bidirectional turbine requires a considerable amount of research and development efforts. Hence, it does not appear economical developing a new machine for any new application. Moreover, in an early design stage of an OWC-system not all information of the wave climate at a particular site may be available. Sometimes, turbine designers are confronted with even ambiguous data from the designer of the collector: Instantaneous, peak and average quantities of pressure, pneumatic power etc. are confused. This are the reasons why we proposed a strategy for selecting a turbine from a given family of turbine types, utilizing standard scaling laws and a simple time domain model for the idealized cyclic operation of the turbine. In this paper only reaction type of turbines (axial-flow Wells and mixed-flow turbines by Moisel) with their approximately linear pressure head/volume flow rate characteristics were considered. As a result, the procedure described yields first estimates of turbine size and rotor speed, number for stages or flows, and performance curves. Alternative type of turbines such as the impulse turbine may need different modelling.

The turbine obtained by our method may also serve as a starting configuration for a refined analysis. In this paper the optimal size and rotational speed of each turbine type considered were identified on the basis of only one sea state, the design sea state. In reality, this could be the sea state which is dominant in a particular wave climate. Including all other sea states encountered at a specific site would most likely yield modifications of this initial turbine design. More complex stochastic models are state-of-the-art and are available in the literature.

Our procedure can also be extended to include more details of the turbine performance characteristics such as a hysteresis (a peculiarity of most turbine types, if they are operated beyond their stall margin), asymmetric turbine performance or asymmetric pneumatic power available from the collector. Moreover, if acoustic emission characteristics are available (as for all the turbines developed and tested at the University of Siegen [19]), the turbine sound emission can be taken into account as well.

Finally, the effect of an optional speed control strategy on the effective performance characteristic can be taken into account. Given the optimal turbine for the design sea state, often the turbine speed is adapted when the turbine is facing off-design sea states with large pressure amplitudes. The discussion of speed control strategies is not within the scope of this paper. It is worth to mention, however, that for any turbine type, as long as its working principle is based on change of momentum (in contrast to positive displacement) and the variation of Mach and Reynolds number are moderate, the fundamental scaling laws

$$
\begin{aligned}
& \&_{\propto \infty} n \text { and } \\
& \Delta p_{t s} \propto n^{2}
\end{aligned}
$$

hold true. This inevitably implies that the slope of the characteristic $I^{\mathbb{Q}}=f\left(\Delta p_{t s}\right)$ at any particular operating point becomes less steep as the rotational speed is increased. Resolving eqs. (9) and (10) for $I^{\&}$ and $\Delta p_{t s}$ allows to express the reciprocal slope eq. (16) in terms of relevant variables: 


$$
D_{t s}=\frac{\psi_{t s}}{\phi} \frac{2 \rho}{d} n
$$

Obviously, given the turbine type $\left(\psi_{t s} / \varphi\right)$ and its rotor size $d, D_{t s}$ increases linearly with the rotational speed $n$ the turbine is operated with. The smaller $d$ und the larger $\psi_{t s} / \varphi$, the more the slope is affected by a variation of rotational speed. In case an OWC-collector requires variable impedance, say as a function of sea state, one could take advantage of this effect by implementing the appropriate control strategy for the rotor speed.

\section{Acknowledgment}

Part of this work was supported by Voith Hydro, Heidenheim, Germany and the Bundesministerium für Wirtschaft und Energie (Federal Ministry for Economic Affairs and Energy) of Germany (FKZ 0325396). The authors greatly appreciate this support. We also want to thank Dipl.-Ing. B. Homrighausen for his countless hours of 3D CAD work. Without this work the precise CNC-manufacture of the many model scale turbines designed and tested at the University of Siegen would not have been possible. Finally, the authors also want to express their thanks to the reviewers with their very helpful comments.

\section{References}

[1] A. A. Wells, Fluid driven rotary transducer, British Patent Spec No. 159570, 1976.

[2] S. Raghunathan, The Wells air turbine for wave energy-conversion," Progress in Aerospace Sciences, 31 (1995), 335-386

[3] C. Moisel, R. Starzmann, Experimental investigation of different stator vane designs for Well turbines. Internal report No. B29 100 014A of the Institute of Fluid- and Thermodynamics, University of Siegen, 2011

[4] R. Starzmann, Th. Carolus, Model-based selection of full-scale Wells turbines for ocean wave energy conversion and prediction of their aerodynamic and acoustic performances. Proc IMechE, Part A: J Power and Energy 228 (1), 2014, 2-16

[5] R. Starzmann, Aero-acoustic analysis of Wells turbines for ocean wave energy conversion. Fortschritt-Bericht VDI Reihe 7 Nr. 500, VDI-Verlag, 2012

[6] R. Starzmann, Th. Carolus, Effect of blade skew strategies on the operating range and aeroacoustic performance of the Wells turbine. ASME J Turbomachinery, 136 (2014) 1-11

[7] R. Starzmann, Guide vanes for Wells turbines: A summary of investigations. Internal report no. B10 002A of the Institute for Fluid- und Thermodynamics, University of Siegen, Jan. 2012

[8] C. Moisel, Th. Carolus, Radial lift-based cascade for bi-directional wave energy air-turbines. Proc. of the ASME Turbo Expo 2014, GT2014-25821, 2014

[9] C. Moisel, Th. Carolus, Novel bidirectional mixed-flow air-turbine for wave energy conversion. 11th European Wave and Tidal Energy Conference, Nantes, France, 2015

[10] C. Moisel, Radiale und diagonale bidirektionale Luftturbinen für den Einsatz in Wellenkraftwerken, PH.D. dissertation University of Siegen, 2016

[11] I. A. Babinstev, Apparatus for converting sea wave energy into electrical energy, US Patent No. 3922739, 1975

[12] T. Setoguchi, M. Takao, Current status of self rectifying air turbines for wave energy conversion, Energy Conversion and Management, 47(2006) 2382-2396

[13] A. F. O. Falcão, L. M. C. Gato, Air Turbines, in Comprehensive Renewable Energy. vol. 8, A. Sayigh (Ed.), Oxford: Elsevier, 2012, 111-149

[14] R. Curran, M. Folley, Air turbine design for OWCs, in Ocean Wave Energy: Current Status and Future Perspectives, J. Cruz (Ed.), Berlin: Springer-Verlag, 2008

[15] A. F. O. Falcão. Stochastic modelling in wave power-equipment optimization: maximum energy production versus maximum profit. Ocean Engineering, 31 (2004) 1407-1421

[16] A. F. O. Falcão, J. C. C. Henriques, L. M. C. Gato. Air turbine optimization for a bottom-standing oscillating-water-column wave energy converter J. Ocean Eng. Mar. Energy (2016) 2:459-472. DOI 10.1007/s40722-016-0045-7 
[17] A.F.O. Falcão, J.C.C. Henriques. "Model-prototype similarity of oscillating-water-column wave energy converters", International Journal of Marine Energy, 6 (2014) 18-34

[18] C. Moisel, Th. Carolus, A facility for testing the aerodynamic and acoustic performance of bidirectional air turbines for ocean wave energy conversion. Renewable Energy 86 (2016) 1340 1352

[19] Th. Carolus, A data base of bidirectional air turbines. Internal report No. B00 100 02A of the Institute of Fluid- and Thermodynamics, University of Siegen, 2015 